\title{
IMPACTO DE LOS SIDERÓFOROS MICROBIANOS Y FITOSIDERÓFOROS EN LA ASIMILACIÓN DE HIERRO POR LAS PLANTAS: UNA SÍNTESIS
}

\author{
IMPACT OF THE MICROBIAL SIDEROPHORES AND PHYTOSIDEROPHORES ON THE IRON \\ ASSIMILATION BY PLANTS: A SYNTHESIS
}

\author{
Gerardo A. Aguado-Santacruz ${ }^{1 \star}$, Blanca Moreno-Gómez ${ }^{1}$, Betzaida Jiménez-Francisco², \\ Edmundo García-Moya ${ }^{2}$ y Ricardo E. Preciado-Ortiz ${ }^{3}$
}

\begin{abstract}
${ }^{1}$ Unidad de Biotecnología y ${ }^{3}$ Programa de Maíz, Campo Experimental Bajío, Instituto Nacional de Investigaciones Forestales y Agropecuarias. Km 6.5 Carretera Celaya-San Miguel de Allende. 38010 Celaya, Gto. México. ${ }^{2}$ Postgrado en Botánica, Colegio de Postgraduados-Campus Montecillo. Km 36.5 Carretera MéxicoTexcoco. 56230, Montecillo, Texcoco, Edo. México.
\end{abstract}

*Autor para correspondencia (gaguado@prodigy.net.mx, aguado.armando@inifap.gob.mx)

\section{RESUMEN}

El hierro ( $\mathrm{Fe})$ es un elemento esencial para prácticamente todos los seres vivos en los que es necesario para importantes funciones celulares como síntesis de ADN, respiración y destoxificación de radicales libres. En la naturaleza se encuentra fundamentalmente en la forma $\mathrm{Fe}^{3+}$ formando parte de sales e hidróxidos de muy baja solubilidad, formas químicas que imposibilitan su uso por algunos seres vivos. La disponibilidad de este elemento es fundamental en el éxito o fracaso de microorganismos patógenos o simbióticos para invadir un organismo o para colonizar un ambiente determinado. Para resolver este problema, muchos organismos, que incluyen bacterias, hongos y plantas, producen pequeñas moléculas, péptidos no ribosomales muchas de ellas, de alta afinidad por el hierro llamadas sideróforos que actúan de manera específica como agentes quelantes para secuestrar hierro en presencia de otros metales y reducirlo a $\mathrm{Fe}^{2+}$, una forma mucho más soluble y aprovechable para su nutrición. Los sideróforos bacterianos han despertado gran interés en los últimos años debido al potencial que tienen para el control biológico de hongos y bacterias fitopatógenas y por constituir un mecanismo de promoción de crecimiento en rizobacterias promotoras del crecimiento vegetal. Los análogos de estas moléculas en las plantas, conocidos como fitosideróforos, también juegan un papel fundamental en la nutrición del hierro en las plantas. La importancia de los fitosideróforos ha recobrado fuerza en virtud del incremento en la salinidad de las aguas de riego y $\mathrm{pH}$ del suelo, producto del abatimiento de los mantos acuíferos que resultan en una reducción de la disponibilidad de hierro. En esta revisión se aportan elementos básicos para entender los tipos, la función, la importancia, interacciones y los mecanismos de acción de los sideróforos de origen bacteriano y vegetal.

Palabras clave: Bacterias promotoras de crecimiento vegetal (BPCV), hierro, sideróforos, fitosideróforos.

\section{SUMMARY}

Iron is an essential element for practically all living organisms, which require it for important cellular functions such as DNA synthesis, respiration and detoxification of free radicals. In nature, it is essentially present in the form of $\mathrm{Fe}^{3+}$ as part of salts and hydroxides of low solubility, which are chemical compounds impossible to be used by some living beings. The availability of this element is fundamental for the success or failure of a symbiotic or pathogen microorganism to invade an organism or colonize an environment. To solve this problem many organisms, including bacteria, fungi and plants, have the ability to produce small molecules of proteic nature that bind iron called siderophores, which act as chelating agents to specifically sequester iron in the presence of other metals to reduce it to $\mathrm{Fe}^{2+}$, a more soluble and usable iron form for their nutrition. Likewise, in recent years the bacterial siderophores have attracted much attention due to their potential for biological control of plant pathogenic fungi and bacteria and because they constitute a mechanism of enhancing growth in plant growth-promoting rhizobacteria. The analogs of these molecules in plants, called phytosiderophores, also play a central role in the iron nutrition of plants. The importance of the phytosiderophores has recovered force due to the reduction of the ground water level that results in an increased salinity of the irrigation water and soil $\mathrm{pH}$, and consequently in a reduction of the iron availability. This review provides elements for understanding the types, function, importance and the action mechanisms of the bacterial and plant siderophores.

Index words: Plant growth promoting rhizobacteria (PGPR), Iron, siderophore, phytosiderophore.

\section{INTRODUCCIÓN}

El hierro es el cuarto metal más abundante en los suelos (Crichton y Charloteaux-Wauters, 1987) y es uno de los micronutrientes esenciales para prácticamente todos los seres vivos, a excepción de las bacterias ácido lácticas en las cuales el manganeso y el cobalto son utilizados en lugar de este metal (Weinberg, 1997). En condiciones fisiológicas, el hierro puede existir en la forma ferrosa $\left(\mathrm{Fe}^{2+}\right)$ o en la forma férrica $\left(\mathrm{Fe}^{3+}\right)$. El potencial de óxido reducción de $\mathrm{Fe}^{2+} / \mathrm{Fe}^{3+}$ hace al hierro extremadamente versátil cuando es incorporado como centro catalítico o como acarreador de electrones (Pandey et al., 1994). Este metal es esencial para 
el metabolismo celular como cofactor numerosas enzimas (Wandersman y Delepelaire, 2004), además de cumplir diversas funciones en procesos biológicos esenciales, como transporte de oxígeno, síntesis de $\mathrm{ADN}$, fijación de nitrógeno, respiración y fotosíntesis (Greenshields et al., 2007). A pesar de su abundancia en la naturaleza, en condiciones fisiológicas (presencia de oxígeno y $\mathrm{pH}$ neutro) este elemento es escasamente disponible debido a la rápida oxidación de $\mathrm{Fe}^{2+}$ a $\mathrm{Fe}^{3+}$ y la subsecuente formación de hidróxidos insolubles (Harrington y Crumbliss, 2009). Un ejemplo de esta oxidación es la que ocurre en la herrumbe de metales en donde la forma férrica del hierro produce el óxido café rojizo, a través de la reacción:

$$
2 \mathrm{Fe}^{3+}+6 \mathrm{OH}^{-} \longrightarrow 2 \mathrm{Fe}(\mathrm{OH})_{3} \longrightarrow \mathrm{Fe}_{2} \mathrm{O}_{3} \cdot 3 \mathrm{H}_{2} 0
$$

En el suelo, la mayor parte del hierro se encuentra formando silicatos de ferromagnesio, hidróxidos u óxidos de hierro, formas que no son fácilmente asimilables por las plantas. Los óxidos e hidróxidos de hierro son los responsables del color rojizo o amarillo de los suelos. El hierro es indirectamente, pero en gran parte, responsable del color verde de las plantas por su importante papel en la producción de clorofila.

En el ambiente, tanto el $\mathrm{pH}$ como los contenidos de materia orgánica, la textura y aireación del suelo afectan la disponibilidad de hierro. La concentración de hierro disponible en el suelo decrece rápidamente a medida que el $\mathrm{pH}$ del suelo incrementa, con un mínimo de alrededor de 7.4 a 8.5; dentro de este rango de valores, la deficiencia por hierro ocurre en la mayoría de los casos, principalmente en suelos calcáreos. En la mayoría de los minerales primarios del suelo el hierro se encuentra como $\mathrm{Fe}^{2+}$, que durante la meteorización llevada a cabo bajo condiciones aeróbicas se precipita como óxidos e hidróxidos de $\mathrm{Fe}^{3+}$ altamente insolubles. Este hecho provoca que en los suelos puedan coexistir óxidos o hidróxidos de hierro con distintas composiciones y grados de cristalización y por tanto con distinta solubilidad. La solubilidad de los óxidos e hidróxidos de $\mathrm{Fe}^{3+}$ presentes en el medio está muy relacionado con el pH del suelo; la solubilidad del hierro desciende 1000 veces por cada unidad que aumenta; la disponibilidad de hierro soluble se reduce a niveles muy bajos cuando el $\mathrm{pH}$ se encuentra alrededor de 7.5 a 8.5 (Lindsay, 1991), como sucede en suelos calizos.

Un nivel de oxígeno reducido ocasionado por anegamiento o compactación puede reducir la disponibilidad de hierro, mientras que la materia orgánica mejora la disponibilidad del hierro al combinarse con este metal para reducir la fijación química o su precipitación como hidróxido férrico. La materia orgánica también puede aumentar la disponibilidad de hierro al favorecer el crecimiento de las poblaciones microbianas, las cuales pueden consumir oxígeno en condiciones de anegamiento o descomponer la materia orgánica para liberar el hierro de los compuestos orgánicos en formas asimilables para las plantas. La materia orgánica también puede ser, por sí misma, una fuente importante de hierro. Por ejemplo, el estiércol de ganado puede contener hasta $8 \mathrm{~kg}$ de hierro por tonelada (Nelson, 2011).

Debido a las reacciones mencionadas previamente que resultan en una baja disponibilidad de hierro, este metal debe ser mantenido en solución por ciertos agentes, como los llamados ligandos (agentes quelantes o queladores). La reacción de un ion metálico divalente o trivalente con un ligando forma un quelato (del griego chelè, pinza, por la disposición en forma de pinza de langosta en que se disponen los ligandos alrededor del hierro; Figura 1). Un quelato es el producto soluble formado cuando ciertos átomos de un ligando orgánico donan electrones al catión. Los grupos carboxilo y los átomos de nitrógeno cargados negativamente poseen electrones que pueden ser compartidos de esta manera. En suelos calcáreos (ricos en $\mathrm{Ca}^{2+}$ y con un $\mathrm{pH}$ generalmente por encima de 7) más de $90 \%$ del cobre y manganeso y la mitad o más del zinc están probablemente quelados con compuestos orgánicos producidos por la microbiota del suelo (Salisbury y Ross, 1992). a)

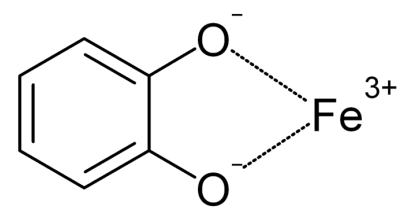

b)

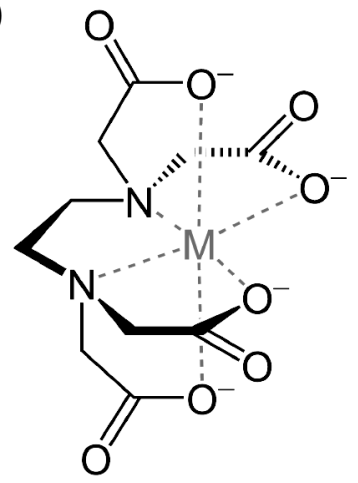

Figura 1. Disposición de ligandos en torno a los iones metálicos. a) Complejo de un sideróforo microbiano del tipo catecolato con $\mathrm{Fe}^{3+}$; b) Quelato formado por el ácido etilendiaminotetraacético (EDTA) con un metal (Holleman y Wiberg, 2001).

Existen dos tipos mayores de ligandos producidos por los seres vivos que forman quelatos con el hierro; a) los fabricados por los microorganismos, conocidos como sideróforos microbianos o simplemente sideróforos, y b) los producidos por las plantas, conocidos como fitosideróforos.

En condiciones aeróbicas el ion ferroso es inestable. A través de la reacción de Fenton y en presencia de agua, el ion 
ferroso genera ion férrico y especies reactivas de oxígeno, las cuales pueden dañar varías distintas macromoléculas (Halliwell y Gutteridge, 1984):

$$
\mathrm{Fe}^{2+}+\mathrm{H}_{2} \mathrm{O}_{2} \longrightarrow \mathrm{Fe}^{3+}+\mathrm{OH} \cdot+\mathrm{OH}^{-}
$$

Posteriormente el ion férrico puede incorporarse a hidróxidos férricos insolubles. Debido a su reactividad, el hierro es secuestrado en diversas proteínas de los organismos como transferrinas, lactoferrinas y ferritinas. Las dos primeras se encuentran de forma extracelular (i.e., en los fluidos de los organismos), mientras que las ferritinas forman parte de las proteínas de almacenamiento de hierro intracelular. Las ferritinas son los compuestos de almacenamiento primario del hierro para la mayoría de organismos, y se encuentran en animales y en plantas (fitoferritinas) y microorganismos (bacterioferritinas). Las bacterioferritinas se ubican tanto en bacterias como en hongos, y difieren de las ferritinas animales y vegetales en que poseen un grupo hemo unido (Andrews, 1998). En todos estos organismos las ferritinas cumplen funciones similares, i.e., cuando las células crecen en abundancia de este metal, funcionan como fuentes de almacenamiento de hierro que son utilizadas al bajar los niveles de este metal. Se han publicado diversas revisiones detalladas sobre la estructura de las ferritinas animales (Powell, 1998), vegetales (Briat et al., 2010) y microbianas (Andrews, 1998), por lo que no se abordarán en la presente obra.

Cuando un microorganismo ingresa a un organismo hospedero, ya sea en forma patógena o simbiótica, encuentra un ambiente favorable con acceso a prácticamente todos los nutrientes necesarios para su crecimiento a excepción de uno, el hierro. El hierro, a diferencia de otras fuentes elementales para la nutrición, como nitrógeno, fósforo, potasio y demás macro- y micronutrientes, no se encuentra libremente disponible en los organismos hospederos, por lo que constituye un factor limitante importante para el crecimiento de los microorganismos. Se sabe que una de las respuestas de los organismos hospederos al ataque de patógenos consiste en la reducción del hierro libre mediante el secuestro de este metal en las moléculas de ferritina. Este mecanismo opera tanto en animales como en plantas, aunque una diferencia notable es que en los primeros el control de la síntesis de ferritina ocurre a nivel traduccional, mientras que en plantas ocurre a nivel transcripcional (Briat et al., 1999; Dellagi et al., 2005).

Los microorganismos que habitan en un organismo hospedero en forma patógena o simbiótica pueden utilizar el hierro del organismo que los alberga extracelularmente a partir de las transferrinas, lactoferrinas o hidróxidos férricos, o intracelularmente a partir de la hemoglobina o ferritinas (Krewulak y Vogel, 2008). En el caso de la hemoglobina, las bacterias destruyen los eritrocitos e hidrolizan la hemoglobina para poder tener acceso a los grupos hemo portadores del hierro. La captación directa de hierro es realizada por algunos microorganismos anaeróbicos, como Clostridium perfrigens, que son capaces de captar hierro y crear a su alrededor un microambiente de pH más ácido (Neilands, 1995). Este ambiente reductor favorece la aparición de especies químicas más solubles formadas por $\mathrm{Fe}^{2+} \mathrm{y}$ además facilita la liberación del metal presente en las proteínas (lactoferrina y transferrina) del organismo hospedero (Neilands, 1995). La captación de hierro mediante este mecanismo involucra la actividad ferroreductasa en la membrana plasmática que reduce $\mathrm{Fe}^{3+}$ a $\mathrm{Fe}^{2+}$. En este estado, el hierro es incorporado al interior de la célula por un sistema de transporte presente también en la membrana.

Cuando los microorganismos se encuentran en forma libre en el suelo sin establecer alguna relación simbiótica o parasítica con organismos hospederos, la problemática en torno a la adquisición del hierro plantea un escenario distinto. Normalmente este elemento presenta baja disponibilidad debido a su baja solubilidad en ambientes aeróbicos de $\mathrm{pH}$ neutro o alcalino (Alexander y Zuberer, 1991; Hissen et al., 2005). Sin embargo, en algunos suelos alcalinos la concentración de hierro en solución es a menudo más alta de la esperada, incremento que se atribuye precisamente a la presencia de moléculas orgánicas que exhiben diversas capacidades para quelatar el hierro (Lindsay, 1991). Entre éstas destacan los sideróforos producidos por muchos microorganismos para resolver la problemática en torno a la baja disponibilidad de hierro (Harrington y Crumbliss, 2009), de tal forma que, por ejemplo, la bacteria aeróbica Pseudomonas mendocina que es capaz de proliferar en medio con hematita $\left(\alpha-\mathrm{Fe}_{2} \mathrm{O}_{3}\right)$ como única fuente de hierro (Dehner et al., 2010).

Los sideróforos microbianos son moléculas secretadas por microorganismos en condiciones de deficiencia de hierro para secuestrar el hierro de su entorno (Figura 2). Los sideróforos (del griego sideros phoros "portadores o acarreadores de hierro") son moléculas de bajo peso molecular de 0.5 a $1.0 \mathrm{kDa}$, solubles en soluciones acuosas a $\mathrm{pH}$ neutro (Dybas et al., 1995) que son sintetizados por bacterias, principalmente Gram negativas, hongos, levaduras y algunas plantas (fitosideróforos), particularmente gramíneas (Drechsel y Jung, 1998) y que actúan como agentes quelantes específicos de $\mathrm{Fe}^{3+}$. La característica principal de este tipo de moléculas es que poseen una elevada constante de disociación de hierro, que oscila entre $10^{22}$ y $10^{55}$ (Neilands, 1995). La síntesis de estas moléculas incrementa cuando los microorganismos se encuentran en condiciones limitativas de hierro (Ratledge y Dover, 2000; Clark, 2004). La afinidad tan elevada de 
estas moléculas por el hierro facilita la captación de este metal a partir de compuestos como hidróxido férrico, y de proteínas del organismo hospedero como transferrina o ferritina (Drechsel y Jung, 1998; Neilands, 1995).

Los complejos que forman los sideróforos con el hierro en el suelo son asimilados eficientemente tanto por el microorganismo que los producen como por otros microorganismos habitan en las cercanías (Winkelmann, 1991); se ha demostrado que la concentración de este complejo es en ocasiones lo suficientemente alta para beneficiar la nutrición de las plantas (Crowley et al., 1987). De hecho, los exudados radicales, particularmente los compuestos fenólicos, tienen un efecto importante en la proliferación de microorganismos productores de sideróforos en la rizosfera de las plantas, especialmente en situaciones de baja disponibilidad de hierro (Jin et al., 2010)

Es precisamente a través de la síntesis de sideróforos que algunas bacterias presentes en el suelo influyen de manera positiva en el crecimiento de las plantas. Existen numerosas referencias que describen el uso de bacterias asociadas con plantas para estimular su crecimiento y como agentes mejoradores del suelo y de la sanidad vegetal (e.g., Welbaum et al., 2004). Este grupo de bacterias son llamadas rizobacterias (o simplemente bacterias) promotoras del crecimiento de las plantas (RPCV o BPCV) (Kloepper y Schroth, 1978; Glick et al., 1999), también conocidas como PGPR's por sus siglas en inglés (plant growth promoting rhizobacteria). Aunque en algunos casos las plantas pueden aprovechar de manera eficiente los sideróforos microbianos, son sus propios queladores de hierro, conocidos como fitosideróforos, los que principalmente les permitirán sobrevivir en suelos con baja disponibilidad de hierro. El grado de disponibilidad de hierro para una planta en un ambiente determinado dependerá, entre otros factores, de las afinidades y concentraciones relativas de los queladores microbianos y vegetales (Crowley et al., 1991).

El objetivo de esta revisión es actualizar y sintetizar de manera clara y concreta la participación de los sideróforos y fitosideróforos en la nutrición vegetal, mediante el análisis de las interacciones y modos de acción de estas moléculas sobre la bioquímica y fisiología de las plantas.

\section{SIDERÓFOROS MICROBIANOS}

Para enfrentar la baja disponibilidad del hierro en el suelo, ciertos microorganismos como Lactobacillus se han adaptado a utilizar otros metales con menos problemas de adquisición que el hierro (Archibald, 1983), y otros se han adaptado a microambientes anaerobios donde este elemento se encuentra principalmente en su forma
$\mathrm{Fe}^{2+}$, relativamente más soluble (Crichton y CharloteauxWauters, 1987); en cambio, algunas bacterias, anaeróbicas estrictas o facultativas, emplean uno de los mecanismos de asimilación de hierro más extendido en el mundo microbiano, la captación de $\mathrm{Fe}^{3+}$ mediada por sideróforos (Ratledge y Dover, 2000).

\section{Tipos de sideróforos microbianos}

Casi todos los sideróforos que se han identificado contienen como grupo ligando al ácido hidroxámico, catecol o al ácido hidroxicarboxílico. De acuerdo con el grupo funcional quelador del hierro, los sideróforos pueden clasificarse en catecolatos (fenolatos), hidroximatos e hidroxicarboxilatos, que forman complejos octaédricos hexadentados con el metal. Algunos sideróforos son más eficaces que otros para quelatar el hierro y la gran diversidad de moléculas producidas por estos microorganismos se relaciona con una amplia variedad de sustratos que pueden usar (Marahiel, 1997; Crosa y Walsh, 2002).

Aunque algunas bacterias producen sólo una clase de sideróforos, otras secretan diversos tipos que las hace más eficientes para colonizar diferentes ambientes. Algunas especies del género Pseudomonas producen sideróforos del tipo hidroximato, entre los que se encuentran la ferribactina y pseudobactina, pero otras más producen moléculas denominadas pioverdinas del tipo catecol. Se ha demostrado que Burkholderia cepacia produce pioquelina (Sokol, 1986), cepabactina (Meyer et al., 1989) y ornibactina (Meyer et al., 1995). En el caso de las enterobacterias, la mayoría de sus miembros sintetizan enterobactina y aerobactina (Kingsley et al., 1995). El primero de estos sideróforos presenta una de las constantes de formación de complejos férricos más elevadas $\left(\mathrm{K}_{\mathrm{f}} 10^{52}\right)$, lo que le permite disociar fácilmente a este metal de la proteína acarreadora de hierro transferrina. Algunas cepas de Escherichia coli, Shigela y Salmonella son capaces de sintetizar un segundo sideróforo conocido como aerobactina.

Adicionalmente, hay bacterias capaces de utilizar no sólo los sideróforos que sintetizan, sino también los producidos por otras especies bacterianas e incluso por hongos (Morrissey et al., 2000). Bacterias como Mycobacterium o Nocardia producen dos tipos de sideróforos; unos de tipo intracelular (al parecer anclados a la membrana plasmática) y otros de tipo extracelular o exoquelinas que permiten la captación del hierro desde las distintas fuentes del huésped (De Voss y Rutter, 1999). La necesidad de la existencia de estos sideróforos intracelulares podría deberse a la gruesa envoltura lipoproteíca que presentan estas especies bacterianas en su pared (De Voss y Rutter, 1999). 


\section{Importancia de los sideróforos en las bacterias promotoras de crecimiento vegetal}

Las BPCV se caracterizan por su capacidad de estimular el crecimiento de las plantas, a través de mecanismos de tipo directo o indirecto. La estimulación directa puede incluir fijación de nitrógeno (Sessitsch et al., 2002), producción de hormonas (Perrine et al., 2004; García de Salamone et al., 2001), reducción de los niveles de etileno en el suelo (Saleem et al., 2007), solubilización de fosfatos (Rodriguez y Fraga, 1999) y secreción de sideróforos (Carson et al., 2000; Madigan y Martinko, 2005), entre otros. La estimulación indirecta del crecimiento de plantas incluye una variedad de mecanismos de biocontrol que son ampliamente reconocidos como la competencia por nicho ecológico o sustratos, producción de antibióticos (Hassan et al., 1997; Essalmani y Lahlou, 2003), inducción de resistencia sistémica (IRS) a un amplio espectro de patógenos (Bloemberg y Lugtenberg, 2001; Hass et al., 2002) y la producción de sideróforos como un mecanismo de secuestrar el hierro disponible en el medio y con esto limitar el crecimiento de microorganismos fitopatógenos (O'Sullivan y O'Gara, 1992; Dowling et al., 1996). Este es un mecanismo de promoción de crecimiento muy difundido entre las bacterias, inclusive en las que son más reconocidas por otras actividades de estimulación de crecimiento. Recientemente se ha encontrado que, por ejemplo, la bacteria Azospirillum brasilense, distinguida por su capacidad para fijar nitrógeno y producir ácido indolacético (AIA), también es capaz de controlar al hongo fitopatógeno Colletotrichum acutatum en cultivos de fresa mediante la producción de sideróforos (Tortora et al., 2011).

Las bacterias promotoras del crecimiento vegetal que poseen la capacidad de producir sideróforos secuestran el hierro al formar un complejo $\mathrm{Fe}^{3+}$-sideróforo, mediante un receptor específico localizado en la membrana bacteriana, lo cual ocasiona que este metal no se encuentre disponible para otros microorganismos que carezcan del sistema de asimilación específico para reconocer dicho complejo. De esta manera, al utilizar todo o la mayoría del hierro disponible en el suelo suprime o inhibe el crecimiento de otros microorganismos patógenos (o benéficos) presentes en la rizosfera (Compant et al., 2005; Schroth y Hancock, 1982). Se ha demostrado que los sideróforos pueden, por sí mismos, actuar como activadores eficientes de los sistemas de resistencia sistémica inducida en las plantas (Ran et al., 2005; Meziane et al., 2005; Bakker et al., 2007). La capacidad de los sideróforos para actuar como supresores de patógenos depende de la planta, del fitopatógeno a controlar, la composición del suelo, la bacteria y la afinidad del sideróforo por el hierro (Glick, 1995; Dellagi et al., 2009). Las plantas no se ven afectadas por el secuestro de hierro por parte de las rizobacterias, ya que la mayoría de ellas son capaces de crecer en medios con concentraciones de $\mathrm{Fe}^{3+}$ mucho menores que los microorganismos (O`Sullivan y O'Gara, 1992), además de que algunas son capaces de utilizar los complejos $\mathrm{Fe}^{3+}$-sideróforo bacterianos.

\section{Mecanismo de transporte del hierro al interior de las células microbianas}

En respuesta a la restricción de hierro en el ambiente, los genes involucrados en la producción y captura de sideróforos microbianos son des-reprimidos, lo que conlleva a un aumento en la fabricación de estas moléculas así como de las proteínas involucradas en su captura. En situaciones de altas concentraciones de hierro en el medio, las proteínas microbianas represoras dependientes de $\mathrm{Fe}^{2+}$ se unen al ADN ubicado antes de los genes involucrados en la producción de sideróforos, lo que impide su síntesis. En condiciones de bajas concentraciones de hierro, el $\mathrm{Fe}^{2+}$ se disocia de las proteínas represoras lo que activa la transcripción de los genes involucrados en la síntesis de los sideróforos microbianos.

En bacterias Gram negativas y bacterias Gram positivas ricas en AT (adenina y timina), este proceso es usualmente regulado por el represor Fur (ferric uptake regulator o regulador de la captura de hierro férrico), una metaloproteína de zinc (Althaus et al., 1999), mientras que el regulador DtxR realiza esta función en bacterias Gram-positivas ricas en GC (guanina y citosina; Miethke y Marahiel, 2007). Los sideróforos son entonces secretados al ambiente extracelular donde secuestran y solubilizan el hierro. A continuación, los sideróforos son reconocidos por receptores específicos ubicados en la membrana externa de la célula (Neilands, 1995). En este punto, el complejo $\mathrm{Fe}^{3+}$ sideróforo puede ser utilizado por las bacterias a través de dos mecanismos (Figura 2).

En muchos casos, todo el complejo $\mathrm{Fe}^{3+}$-sideróforo es transportado activamente a través de la membrana celular, mientras que en hongos y otros eucariotes el complejo $\mathrm{Fe}^{3+}$ sideróforo puede ser reducido extracelularmente a $\mathrm{Fe}^{2+}$ (Figura 2).

Acoplados a los mecanismos de captación de hierro se encuentran los sistemas encargados de transportar el hierro hacia el interior de la célula. Existen dos mecanismos generales a través de los cuales los microorganismos asimilan el hierro del organismo hospedero. El primero involucra la adquisición de hierro a través de receptores cognados que usan queladores de hierro de bajo peso molecular llamados sideróforos (adquisición indirecta); el segundo consiste en la adquisición de hierro mediada por receptores a partir de proteínas acarreadoras de hierro (adquisición directa). La principal diferencia entre estos dos 
mecanismos consiste en que los sideróforos y las moléculas hemo pueden ser tomadas por las células bacterianas como moléculas intactas, mientras que en el segundo caso el hierro debe ser extraído de las proteínas acarreadoras de hierro (transferrina, lactoferrina) antes de ser transportadas hacia las células bacterianas (Krewulak y Vogel, 2008). La captura del hierro a partir de la transferrina, lactoferrina, hemoglobina y sideróforos se ha identificado en bacterias Gram negativas y Gram positivas.

En las bacterias Gram negativas la membrana externa es una barrera permeable que protege a las bacterias de toxinas, enzimas y detergentes. La presencia de porinas en la membrana externa permite la difusión pasiva de pequeños solutos. La transferrina, lactoferrina, hemoglobina $y$ los complejos $\mathrm{Fe}^{3+}$-sideróforo exceden el tamaño de las aberturas de las porinas y por tanto requieren receptores externos de membrana específicos para la internalización

Mecanismo 1

$\mathrm{Fe}^{3+}$-sideróforo

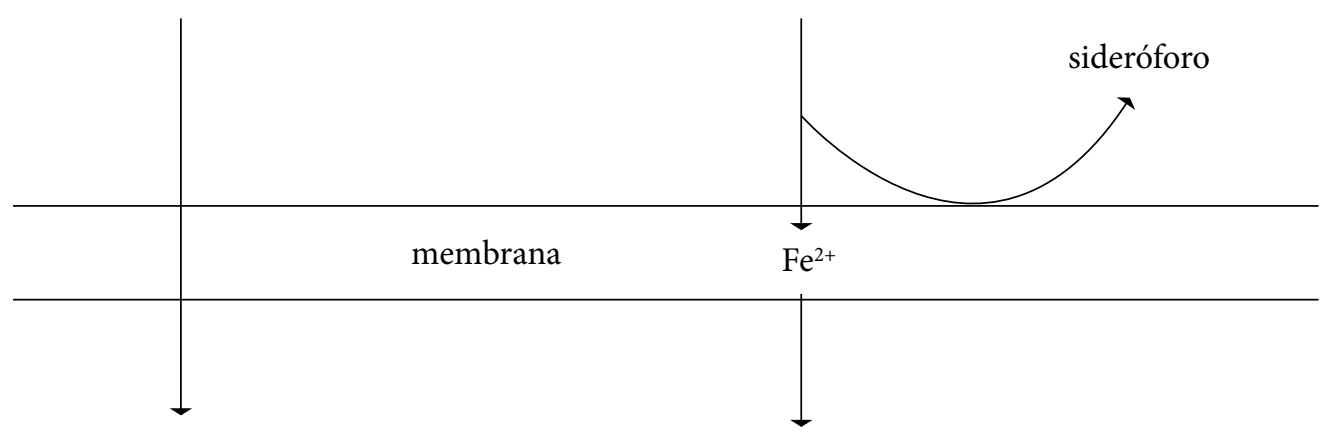

$\mathrm{Fe}^{3+}$-sideróforo

Reducción lenta

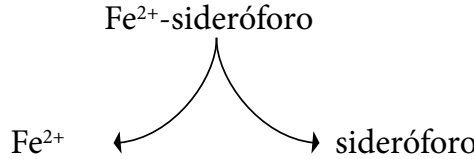
(Moeck y Coulton, 1998).

Mecanismo 2

\section{RIZOSFERA}

$\mathrm{Fe}^{3+}$-sideróforo

al espacio periplásmico. A diferencia del transporte vía porinas, los complejos sideróforo-receptor presentan constantes de disociación extremadamente pequeñas que van de $10^{6}$ a $10^{9}$, lo cual permite una máxima eficiencia de internalización a concentraciones muy bajas de ligando

El proceso completo requiere de un receptor de membrana externo, una proteína de unión periplásmica (PBP) y un transportador membranal interno del tipo ABC (ATP-binding cassette proteins o proteínas de unión al casete de ATP; Roosenberg et al., 2000; Köster, 2001). Las bacterias Gram negativas carecen de un gradiente de iones o ATP establecido para generar la energía requerida para el transporte. Este requerimiento energético es obtenido a través del acoplamiento de la fuerza protón de la membrana citoplásmatica a la membrana externa a través de las proteínas TonB, ExbB y ExbD (Elkins et al., 1998; Figura 3).

Figura 2. Mecanismos de los sideróforos microbianos para la captura y solubilización de hierro (Neilands, 1995). 
A diferencia de las bacterias Gram negativas, las Gram positivas carecen de membrana externa. En este tipo de bacterias la envoltura celular comprende la membrana plasmática, una membrana constituida por una gruesa capa de peptidoglicanos que rodea a la anterior. La pared celular se une a la membrana citoplasmática mediante moléculas de ácido lipoteicoico. Entonces, una pared compuesta de mureína, polisacáridos, ácidos teicoicos y proteínas de la pared celular es todo lo que separa al citoplasma de las bacterias de su entorno. Esto sugiere que el tamaño relativamente pequeño de los sideróforos que producen les permite difundirse libremente a través de la pared bacteriana, desde el interior celular hacia el medio externo (Ratledge y Dover, 2000). Sin embargo, existen mecanismos de recepción específica donde el complejo $\mathrm{Fe}^{3+}$-sideróforo es reconocido por proteínas específicas ancladas en la membrana plasmática (semejantes a las proteínas PBP de las bacterias Gram negativas) y posteriormente transportado por el complejo $\mathrm{ABC}$-dependiente de permeasas al interior de la célula (Morrissey et al., 2000). El paso a través de la membrana citoplasmática es menos específico que la traslocación a través de la membrana externa (Köster, 2001).

Una vez que el complejo $\mathrm{Fe}^{3+}$-sideróforo ha ingresado al citoplasma puede llevarse a cabo su reducción a través de una reductasa de membrana aprovechando un entorno periplásmico con $\mathrm{pH}$ bajo o reductor (Bagg y Neilands, 1987). En Bacillus spp (Gaines et al., 1981), Escherichia coli (Fisher et al., 1990) y Pseudomonas aeruginosa (Cox, 1980) se ha identificado un gran número de reductasas citoplásmaticas del complejo $\mathrm{Fe}^{3+}$-sideróforo. En todos estos casos se utiliza como agente reductor al NADH y al NADPH como fuente de electrones (Bagg y Neilands, 1987). Una vez ubicado en el citoplasma de las células, el complejo $\mathrm{Fe}^{3+}$-sideróforo es reducido lentamente para formar un complejo $\mathrm{Fe}^{2+}$-sideróforo a partir del cual el $\mathrm{Fe}^{2+}$ es liberado finalmente en el citoplasma (Figura 3). Esto ocurre principalmente en el caso de ligandos de sideróforo débiles, como hidroxamatos y carboxilatos. La descomposición de sideróforos u otros procesos biológicos también pueden liberar el hierro (Roosenberg et al., 2000), especialmente en el caso de catecolatos como la enterobactina férrica. Entonces el hierro liberado puede interaccionar con las distintas proteínas bacterianas que lo usan como cofactor. Asimismo, el $\mathrm{Fe}^{2+}$ internalizado puede asociarse a proteínas como porfirinas por la vía de las ferroquelatasas (Dailey y Lascelles, 1977), o con apoproteínas para formar complejos que incorporan este metal en su estructura.
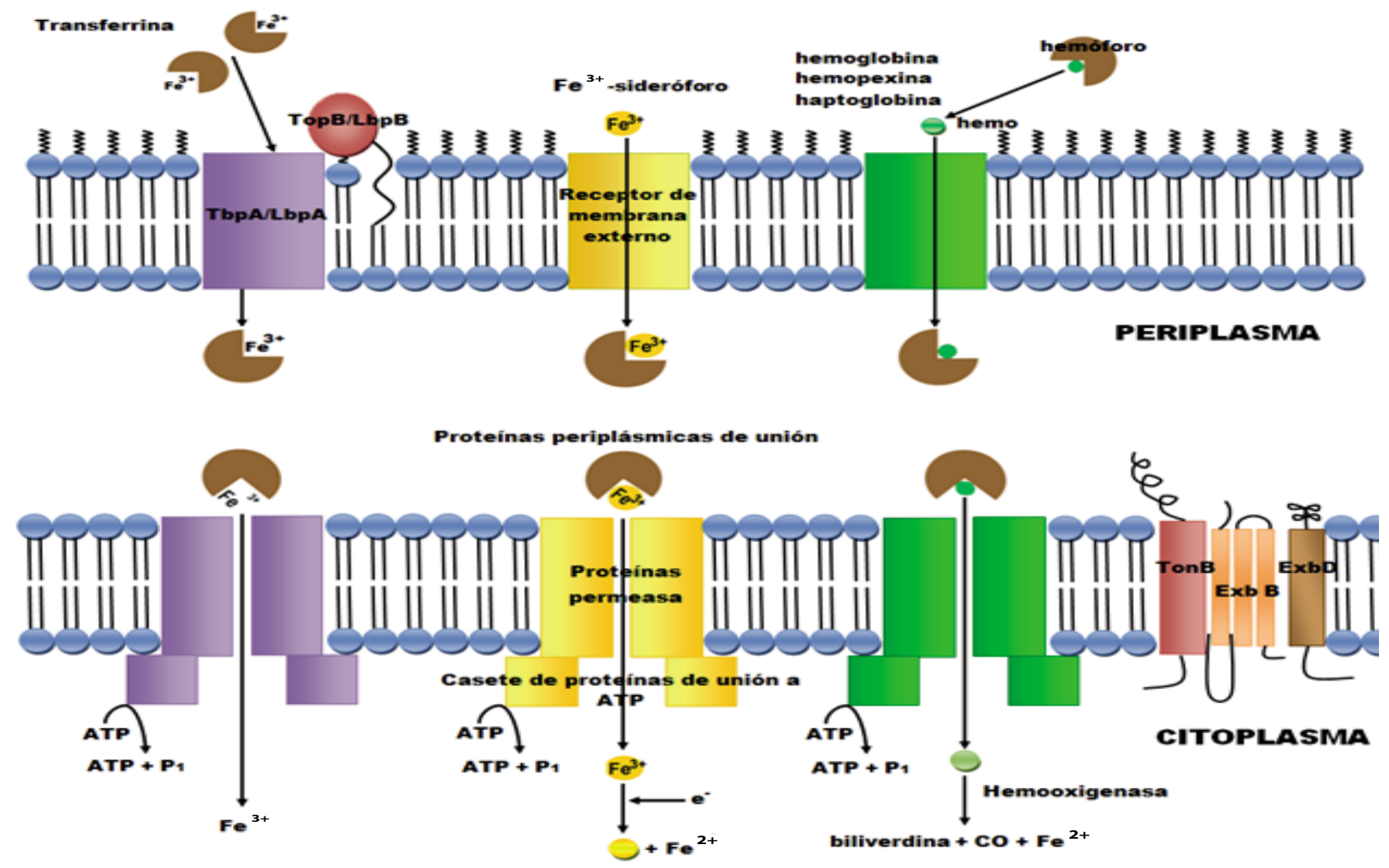

Figura 3. Captura de hierro en bacterias Gram negativas (Krewulak y Vogel, 2008). 


\section{FITOSIDERÓFOROS}

Las plantas enfrentan el problema de la baja disponibilidad de hierro en el suelo a través de dos estrategias generales. La estrategia I es empleada principalmente por plantas dicotiledóneas y monocotiledóneas no gramináceas, mientras que la estrategia II es utilizada solamente por las gramíneas (Lemanceau et al., 2009). Las plantas de estrategia I incrementan la solubilidad del hierro y liberan hacia la rizosfera protones y agentes reductores o quelantes, como ácidos orgánicos y fenoles (Figura 4). La secreción de protones es mediada a través de una ATPasa del tipo P localizada en el plasmalema. El hierro solubilizado es entonces reducido de $\mathrm{Fe}^{3+}$ a Fe ${ }^{2+}$ por medio de una reductasa ubicada en la membrana plasmática de las células epidérmicas de la raíz y a continuación es capturado por un transportador específico para $\mathrm{Fe}^{2+}$. La actividad de la reductasa del quelado de $\mathrm{Fe}^{3+}$ se incrementa significativamente en condiciones de deficiencia de hierro.

Los genes que codifican esta enzima se han clonado a partir de Arabidopsis thaliana (FR02), chícharo (FR01) y tomate (FR01). El paso final en la adquisición de hierro en plantas de la estrategia I es el transporte del $\mathrm{Fe}^{2+}$ a través de la membrana plasmática. Este proceso es mediado por un transportador de $\mathrm{Fe}^{2+}$, (IRT1, iron regulated transporter o transportador regulado por hierro; Figura 4). Posterior a la adquisición primaria de hierro, este elemento debe ser transportado y distribuido en la planta. El proceso se realiza vía xilema, mediante el complejo Fe-citrato, que a su vez es traslocado por transportadores MATE (multidrug and toxic compound extrusión). A partir de este complejo, el hierro debe ser introducido al espacio intracelular mediante las proteínas YSL, identificadas primeramente en Arabidopsis (Conte y Walker, 2011).

Se tiene evidencia que bacterias como Bacillus subtilis activan directamente la estrategia I de adquisición de hierro en plantas de Arabidopsis thaliana, esto sin que la bacteria colonice las raíces de la planta; este mecanismo se explica mediante la producción de ácidos orgánicos volátiles producidos por el microorganismo. Estos compuestos, además de acidificar el medio, desempeñan funciones de señalización que activan la expresión de IRT1 y FR02, para permitir una adecuada asimilación de hierro en las plantas en condiciones limitativas de este elemento (Zhang et al., 2009).

La estrategia II consiste en la producción de moléculas llamadas fitosideróforos que hacen una función análoga a la de los sideróforos microbianos, i.e., facilitar la solubilización y el aprovechamiento del hierro por las plantas. Algunos autores prefieren la utilización del término fitometalóforos (Marschner et al., 1986) en lugar de fitosideróforos, ya que además de hierro, estas moléculas también pueden quelatar otros metales como zinc.

Los fitosideróforos son aminoácidos no proteicos sintetizados por las plantas en condiciones de deficiencia de minerales como hierro y zinc (Susuki et al., 2006; Suzuki et al., 2008). Estas moléculas conforman ligandos hexadentados que coordinan el ion metálico con sus grupos aminos y carboxilos. La producción de fitosideróforos fue estudiada por primera vez en plantas de arroz y avena (Takagi, 1976). Posteriormente, otras sustancias de esta naturaleza se han aislado de exudados radicales de diversas
Estrategia I

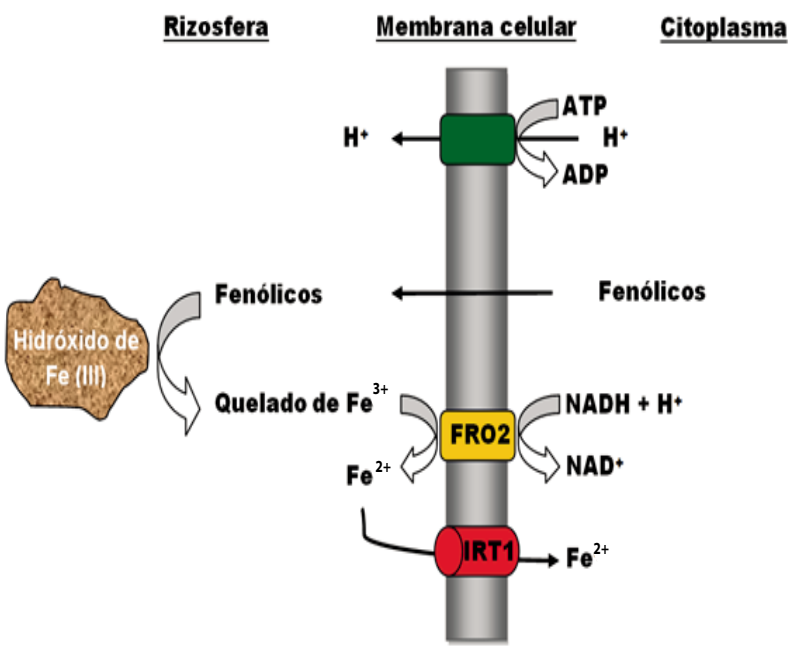

Estrategia II

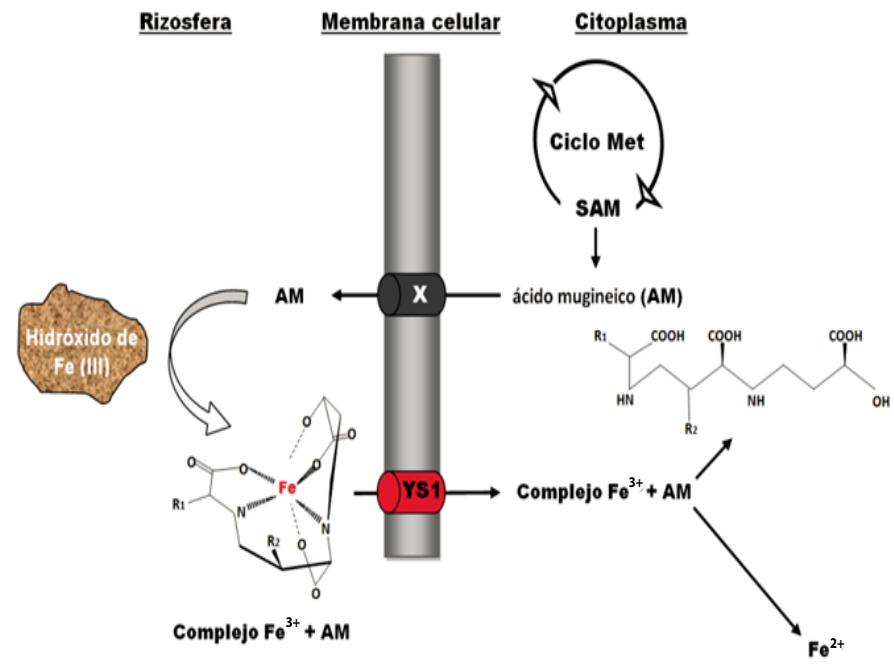

Figura 4. Estrategias de adquisición de hierro por las plantas (Ma, 2005). 
gramíneas como cebada (Takemoto et al., 1978), trigo (Nomoto et al., 1981), avena (Fushiya et al., 1980) y centeno (Nomoto et al., 1979). Estos compuestos cumplen un papel clave en la adquisición de hierro de muy baja solubilidad presente en el suelo (Ma y Nomoto, 1996); esta adquisición es más efectiva que la reducción utilizada por otras plantas para hacer disponible el hierro, si se toma en cuenta que las gramíneas sobreviven en suelos calcáreos.

Con estudios efectuados sobre la interacción entre los fitosideróforos producidos por el trigo y el oxihidróxido de hierro más abundante en el suelo, la goetita, Reichard et al. (2005) demostraron que los fitosideróforos producidos por esta planta pueden movilizar eficientemente el hierro a partir de esta forma insoluble. Por otro lado, el arroz presenta un sistema único de asimilación de hierro que combina las dos estrategias de adquisición de hierro mencionadas previamente (Ishimaru et al., 2006), pero es evidente que este cultivo se encuentra bien adaptado a condiciones donde el $\mathrm{Fe}^{2+}$ es más abundante que $\mathrm{el} \mathrm{Fe}^{3+}$.

Los fitosideróforos se clasifican dentro del grupo de los ácidos mugineicos que incluyen al ácido mugineico, que fue el primer fitosideróforo descubierto (Sugiura et al., 1981), el ácido 2-desoximugineico, el ácido 3-epi-hidroximugineico, el ácido avénico y el ácido 3-epihidroxi-2-desoximugineico.

La síntesis de los fitosideróforos en la raíz es inducida por la deficiencia de hierro en el suelo. La producción de estas moléculas tiene lugar durante el día y se acumulan dentro de las células corticales para ser secretados durante la mañana siguiente (Ma y Nomoto, 1996). Se han hecho diversos esfuerzos para dilucidar las rutas biosintéticas de los ácidos mugineicos, tanto in vivo como in vitro. Los resultados obtenidos sugieren que la L-metionina es el precursor en la biosíntesis de este grupo de fitosideróforos (Kawai et al., 1988; Shojima et al., 1990). La mayoría de sideróforos microbianos posee grupos hidroxamato o fenolato, mientras que los fitosideróforos consisten de grupos carboxilo, amino e hidroxilo como grupos funcionales de los ligandos (Sugiura y Nomoto, 1984).

La síntesis de la L-metionina se asocia con el ciclo de la metionina (Ma et al., 1995). Todos los fitosideróforos compartenla misma víabiosintética a partirdelaL-metionina al ácido 2'-desoximugineico (DMA) vía nicotinamina, pero los pasos siguientes difieren entre especies y cultivares de plantas. Las enzimas nicotinamina sintasa y nicotinamino transferasa son fundamentales en la ruta biosintética del grupo del ácido mugineico. Varios estudios han revelado que la expresión de estas enzimas incrementa en condiciones de deficiencia de hierro (Mori, 1999). El ácido mugineico es sintetizado a partir de la L-metionina vía nicotinamina (NA), mediante la condensación inicial de tres moléculas de S-adenosil metionina (SAM) para producir una molécula de nicotinamina. Este proceso es catalizado por la enzima nicotinamina sintasa (NAS). Aunque la nicotinamina es producida por plantas monocotiledóneas y dicotiledóneas, los pasos subsecuentes para la síntesis de los ácidos mugineicos son específicos para las gramíneas (Curie y Briat, 2003). La enzima crucial en la ruta biosintética que se lleva a cabo en las gramíneas es la nicotinamina aminotransferasa (NAAT) que cataliza la transferencia del residuo amino a la NA, y entonces la enzima 2-desoximugineico sintasa acelera la producción de ácido 2'-desoximugineico, precursor del resto de los ácidos mugineicos (Kobayashi et al., 2005) que se producen en etapas sucesivas de hidroxilación.

Para lograr la adquisición del hierro insoluble a partir del suelo, los fitosideróforos deben ser secretados hacia la rizosfera a través de un canal de aniones mediante un gradiente de potasio entre el citoplasma y el exterior de la célula. Experimentos realizados mediante bloqueo de canales aniónicos o por inhibición del gradiente de potasio con valinomicina, demostraron una disminución en la secreción de ácido mugineico (Sakaguchi et al., 1999). El sitio de secreción de los fitosideróforos se localiza en la región apical de la raíz.

Los genes responsables de la secreción de fitosideróforos no se han identificado. Después de su secreción, los fitosideróforos solubilizan el hierro del suelo por quelación. Todos los fitosideróforos forman un complejo con el hierro en una proporción de 1:1 (Nomoto et al., 1981). Entonces el complejo $\mathrm{Fe}^{3+}$-fitosideróforo es transportado a través de la membrana plasmática de las células corticales como una molécula no disociada (Figura 4). El gen YSI, identificado en maíz, es necesario para la introducción del complejo $\mathrm{Fe}^{3+}$-fitosideróforo al citoplasma (Curie et al., 2001). Los transportadores ZmYSI y HvYSI de maíz y cebada, respectivamente, se han caracterizado y comparado en términos de expresión en respuesta a cambios diurnos y por su localización en el tejido. Se encontró que la expresión de ZmYSI no presentó variaciones durante el día y se localizó en células epidémicas de la raíz y en células del mesófilo, pero no en células epidérmicas de hojas. Mientras tanto, HvSYI sólo se localizó en raíz y mostró cambios de expresión durante el día. Ambos transportadores se activaron en condiciones de déficit de hierro, pero no de otros metales como $\mathrm{Zn}$, Cu o Mn (Ueno et al., 2009).

La síntesis de fitosideróforos es dependiente de la especie vegetal, ya que plantas como cebada y centeno sintetizan mayoritariamente fitosideróforos hidroxilados, mientras que los no hidroxilados predominan en especies como maíz $\mathrm{y}$ arroz. Al tener como precedente estas observaciones, Von Wirén et al. (2000) hicieron estudios para verificar si 
la estructura de los fitosideróforos influía en el proceso de asimilación de hierro; demostraron que cuando aumentaba el número de hidroxilaciones también incrementaba la estabilidad del complejo $\mathrm{Fe}^{3+}$-fitosideróforo, lo cual se relacionó con una modificación de la carga neta del complejo, factor muy importante para su movilidad en el suelo (Inoue et al., 1993). Consecuentemente, las plantas que sintetizan fitosideróforos hidroxilados son más resistentes a la clorosis que las que no los sintetizan.

Existe una fuerte correlación entre la cantidad de fitosideróforo que sintetiza la planta y su tolerancia a la deficiencia de hierro (Takagi, 1976; Ma et al., 1999). Especies como cebada, centeno y trigo son más tolerantes a la clorosis férrica que las especies que secretan cantidades menores de estos agentes quelantes, como maíz, sorgo y arroz (Von Wirén et al., 1995). Sin embargo, la cantidad de fitosideróforos secretados no siempre es consistente, ya que puede haber diferencias entre variedades de la misma especie, como se ha reportado en maíz, lo que indica que hay otros factores que controlan la eficiencia de este mecanismo (Von Wirén et al., 1994).

\section{COMPLEJOS $\mathrm{Fe}^{3+}-$ SIDERÓFORO Y $\mathrm{Fe}^{3+}-$ FITOSIDERÓFORO COMO FUENTES DE HIERRO COMUNES PARA LAS PLANTAS Y LOS MICROORGANISMOS}

Los sideróforos microbianos y los fitosideróforos presentan diferencias fundamentales. Además de importantes diferencias químicas estructurales, los fitosideróforos poseen una afinidad relativamente menor por el hierro, una menor diversidad de formas y en algunos casos estas moléculas no quelatan de manera específica el hierro, ya que también poseen capacidad de unir y transportar otros metales, como el zinc. Adicionalmente los fitosideróforos poseen un tamaño relativamente menor (294-336 Da) al de los sideróforos microbianos (500-1000 $\mathrm{Da})$, como reportó Ma (2005).

Las plantas que son capaces de utilizar los complejos $\mathrm{Fe}^{3+}$-sideróforos bacterianos como fuente de hierro (Wang et al., 1993), aumentan sus posibilidades de supervivencia y adaptación a diferentes condiciones de suelo. Existe discusión en cuanto al grado de influencia de los sideróforos microbianos en la nutrición del hierro por las plantas, influencia que puede variar desde muy poca (Bar-Ness et al., 1992; Crowley et al., 1992; Walter et al., 1994) hasta altamente significativa (Jurkevitch et al., 1988; Wang et al., 1993, Yehuda et al., 2000; Sharma et al., 2003). Además se ha encontrado que los sideróforos producidos por Penicillium chrysogenum también pueden ser asimilados como una fuente de hierro en algunas plantas (Hördt et al., 2000).
Contrariamente, los complejos $\mathrm{Fe}^{3+}$-fitosideróforo parecen ser una buena fuente de hierro para las bacterias (Jurkevitch et al., 1993; Marschner y Crowley, 1998). Las interacciones entre los dos tipos de queladores, sideróforos bacterianos y fitosideróforos, dependen de su afinidad hacia el hierro y de sus concentraciones relativas. En comparación con los fitosideróforos, los sideróforos bacterianos, como la pioverdina producida por Pseudomonas fluorescens, tienen una elevada afinidad por el hierro (Yehuda et al., 1996). Si los sideróforos y los fitosideróforos se encuentran presentes en concentraciones similares, el hierro se une preferencialmente a los sideróforos, los cuales pueden remover el hierro fijado al complejo $\mathrm{Fe}^{3+}$-fitosideróforo. En contraste, la rizoferrina producida por el hongo Rhizopus arrhizus tiene una afinidad por el hierro ligeramente mayor que la de los fitosideróforos. El complejo $\mathrm{Fe}^{3+}$-rizoferrina es una buena fuente de hierro para la cebada, debido a la probable transferencia de hierro de la rizoferrina a los fitosideróforos. De este modo los microorganismos parecen ser relativamente más competitivos que las raíces de las plantas para capturar hierro.

Además de la afinidad de los queladores por el hierro, la abundancia relativa de éstos también juegan un papel importante (Yehuda et al., 1996). El ritmo diurno de liberación de fitosideróforos por los pastos resulta en una alta concentración de fitosideróforos en los ápices radicales durante el día (Crowley y Gries, 1994). En estas condiciones, los fitosideróforos pueden ser eficientes queladores de hierro, y pueden incluso remover hierro de sus contrapartes microbianas debido a que la densidad bacteriana es particularmente baja en la punta de la raíz. Finalmente, si una proporción de fitosideróforos es descompuesta por los microorganismos, es probable que un remanente pueda ser utilizado por las plantas.

\section{CONCLUSIONES}

El hierro constituye un elemento de control para el crecimiento de los microorganismos endófitos (patógenos y no patógenos) y rizosféricos, por lo que éstos han desarrollado diferentes estrategias para poder aprovechar las fuentes de hierro presentes tanto en los organismos hospederos como en el suelo. La evidencia experimental sugiere que en ciertas circunstancias las plantas poseen la capacidad de aprovechar los sideróforos microbianos, además de que existen abundantes microorganismos en la rizosfera que pueden utilizar a los fitosideróforos como fuente de carbono o de hierro. El proceso de intercambio depende de la estabilidad de ambos complejos y de otros factores como la concentración relativa o absoluta de los quelatos producidos por la planta y por el microorganismo, del hierro y de otros iones presentes en el suelo, del pH en la solución, y las cinéticas de formación de los complejos 
hierro-sideróforo. Adicionalmente, los sideróforos microbianos juegan un papel clave en el control de microorganismos fitopatógenos, ya sea al secuestrar el hierro y al reducir las cantidades de hierro disponibles para el crecimiento de éstos, o bien por activar los sistemas de resistencia sistémica inducida de las plantas.

\section{PERSPECTIVAS}

La deficiencia de hierro representa un grave problema en México, particularmente en el norte, donde la elevada concentración de sales limita fuertemente la disponibilidad de este elemento. Debido a sus capacidades para secuestrar hierro, los sideróforos microbianos y los fitosideróforos constituyen un área de estudio fundamental de la nutrición de las plantas que se desarrollan en suelos con baja disponibilidad de hierro. El desarrollo de nuevas variedades de plantas, particularmente gramíneas, con capacidades mejoradas para crecer en estos suelos limitativos. i.e., con alta capacidad para producir fitosideróforos, ha sido un objetivo fundamental dentro de los programas de mejoramiento vegetal. En la actualidad también se explora la alternativa de aplicar sideróforos sintéticos como un medio para corregir las deficiencias de hierro en las plantas (Yehuda et al., 2011).

La posibilidad de aislar e identificar microorganismos con una alta capacidad para producción de sideróforos que posean una mayor eficiencia para secuestrar este elemento ha sido menos estudiada, si bien la formulación de biofertilizantes con hongos y bacterias capaces de producir sideróforos, como Pseudomonas spp., se ha incrementado en los últimos años. El análisis bioquímico y fisiológico de plantas productoras de fitosideróforos que crecen en condiciones limitativas de hierro y en presencia de microorganismos hiperproductores de sideróforos altamente afines por este elemento aportará nuevos elementos de juicio para dilucidar el grado de participación de los sideróforos bacterianos en la nutrición de los cultivos, particularmente en los que se desarrollan en suelos marginales.

\section{AGRADECIMIENTOS}

A SAGARPA, por el apoyo otorgado para la realización de este trabajo a través del convenio "Impulso a Nuevos Productos y Procesos de la Bioeconomía y de Investigación, Transferencia de Tecnología y uso de Biocombustibles, Biofertilizantes y Abonos Orgánicos" (No. 2010083110035320100009S19584A410111).

\section{BIBLIOGRAFÍA}

Alexander D B, D A Zuberer (1991) Use of chrome azurol S reagents to evaluate siderophore production by rhizosphere bacteria. Biol.
Fertil. Soils 12:39-45.

Althaus E W, C E Outten, K E Olson, H Cao, T V O'Halloran (1999) The ferric uptake regulation (Fur) repressor is a zinc metalloprotein. Biochemistry 38:6559-6569.

Andrews S C (1998) Iron storage in bacteria. Adv. in Microbial Physiol. 40:281-351.

Archibald F (1983) Lactobacillus plantarum, an organism not requiring iron. FEMS Microbiol. Lett. 19:29-32.

Bagg A, J B Neilands (1987) Molecular mechanism of regulation of siderophore-mediated iron assimilation. Microbiol. Rev. 51:509518.

Bakker P A H M, C M J Pieterse, L C Loon (2007) Induced systemic resistance by fluorescent Pseudomonas spp. Phytopathology 97:239-243.

Bar-Ness E, Y Hadar, Y Chen, A Shanzer, J Libman (1992) Iron uptake by plants from microbial siderophores. A study with 7-nitrobenz-2 oxa-1,3-diazole-desferrioxamine as fluorescent ferrioxamine B analog. Plant Physiol. 99:1329-1335.

Bloemberg G V, B J J Lugtenberg (2001) Molecular basis of plant growth promotion and biocontrol by rhizobacteria. Curr. Op. Plant Biol. 4:343-350.

Briat J F, C Duc, K Ravet, F Gaymard (2010) Ferritins and iron storage in plants. Bioch. Biophys. Acta 1800:806-814.

Briat J F, S Lobreaux, N Grignon, G Vansuyt (1999) Regulation of plant ferritin synthesis: how and why. Cell. Molec. Life Sci. 56:155-166.

Carson K C, J M Meyer, M J Dilworth (2000) Hydroxamate siderophores of root nodule bacteria. Soil Biol. Biochem. 32:11-21.

Clark B L (2004) Characterization of a catechol-type siderophore and the detection of a possible outer membrane receptor protein from Rhizobium leguminosarum strain IARI 312. East Tenn. St. Univ. 43:154-244.

Compant S, B Duffy, J Nowak, C Clement, E A Barka (2005) Use of plant growth-promoting bacteria for biocontrol of plant diseases: principles, mechanisms of action, and future prospects. Appl. Env. Microbiol. 71:4951-4959.

Conte S S, E L Walker (2011) Transporters contributing to iron trafficking in plants. Molec. Plant 4:464-476.

Cox C D (1980) Iron reductases from Pseudomonas aeruginosa. J. Bacteriol. 141:199-204.

Crichton R R, M Charloteaux-Wauters (1987) Iron transport and storage Europ. J. Biochem. 164:485-506.

Crosa J H, C T Walsh (2002) Genetics and assembly line enzymology of siderophore biosynthesis in bacteria. Microbiol. Molec. Biol. Rev. 66:223-249.

Crowley D E, C P P Reid, P J Szaniszlo (1987) Microbial siderophores as iron sources for plants. In: Iron Transport in Microbes, Plants and Animals. G Winkelmann, D Van der Helm, J B Neilands, V C H Weinheim (eds). Germany. pp:375-386.

Crowley D E, D Gries (1994) Modeling of iron availability in the plant rhizosphere. In: Biochemistry of Metal Micronutrients in the Rhizosphere. J A Manthey, D E Crowley, D G Luster (eds). Lewis Publishers, Boca Raton, Florida, USA. pp:199-224.

Crowley D E, V Roemheld, H Marschner, P J Szaniszlo (1992) Rootmicrobial effects on plant iron uptake from siderophores and phytosiderophores. Plant and Soil 142:1-7.

Crowley, D E, Y C Wang , C P P Reid, P J Szaniszlo (1991) Mechanisms of iron acquisition from siderophores by microorganisms and plants. Plant and Soil 130:179-198.

Curie C, J F Briat (2003) Iron transport and signaling in plants. Annu. Rev. Plant Biol. 54:183-206.

Curie C, Z Panaviene, C Loulergue, S L Dellaporta, J F Briat, E L Walker (2001) Maize yellow stripel encodes a membrane protein directly involved in $\mathrm{Fe}$ (III) uptake. Nature 409:346-349.

Dailey H A, J Lascelles (1977) Reduction of iron and synthesis of protoheme by Spirillum itersonii and other organisms. J. Bacteriol. 129:815-20.

De Voss J, J Rutter (1999) Iron acquisition and metabolism by mycobacteria. J. Bacteriol. 181:4443-4451.

Dehner C A, J D Awaya, P A Maurice, J L DuBois (2010) Roles of siderophores, oxalate, and ascorbate in mobilization of iron from hematite by the aerobic bacterium Pseudomonas mendocina. Appl. Env. Microbiol. 76:2041-2048.

Dellagi A, M Rigault, D Segond, C Roux, Y Kraepiel, F Cellier, J F Briat, F Gaymard, D Expert (2005) Siderophore-mediated 
upregulation of Arabidopsis ferritin expression in response to Erwinia chrysanthemi infection. The Plant J. 43:262-272.

Dellagi A, D Segond, M Rigault, M Fagard, C Simon, P Saindrenan, D Expert (2009) Microbial siderophores exert a subtle role in Arabidopsis during infection by manipulating the immune response and the iron status. Plant Physiol. 150:1687-1696.

Dowling D N, R Sexton, A Fenton, I Delany, S Fedi, B McHugh, M Callanan, Y Moenne-Loccoz, F O'Gara (1996) Iron regulation in plant associated Pseudomonas fluorescens M114: implication for biological control. In: Molecular Biology of Pseudomonads. T Nakazawa (ed). American Society for Microbiology, Washington, DC, USA. pp:502-511.

Drechsel H, G Jung (1998) Peptide siderophores. J. Peptide Sci. 4:147-181.

Dybas M, G Tatara, C S Criddle (1995) Localization of carbon tetrachloride transformation activity of Pseudomonas sp strain KC. Appl. Env. Microbiol. 61:758-762.

Elkins C, P A Totten, B Olsen, C E Thomas (1998) Role of the Haemophilus ducreyi Ton system in internalisation of heme from hemoglobin. Infect. Immun. 66:151-60.

Essalmani H, H Lahlou (2003) Mécanismes de bioprotection des plantes de lentile par Rhizobium leguminosarum contre Fusarium oxysporum sp. Lentis. Comp. Rend Biol. 326:1163-1173.

Fisher E, B Strehlow, D Hartz, V Braun (1990) Soluble and membranebound ferrisiderophore reductases of Escherichia coli K-12. Arch. Microbiol. 153:329-336.

Fushiya S, Y Sato, S Nozoe, K Nomoto, T Takemoto, S Takagi (1980) Avenic acid A, a new amino acid possessing an iron-chelating activity. Tetrahedron Lett. 21:3071-3072.

Gaines C G, J S Lodge, J E L Arceneaux, B R Byers (1981) Ferrisiderophore reductase activity associated with an aromatic biosynthetic complex in Bacillus subtilis. J. Bacteriol. 148:527-533.

García de Salamone I E, R K Hynes, L M Nelson (2001) Cytokinin production by plant growth promoting rhizobacteria and selected mutants. Can. J. Microbiol. 47:404-411.

Glick B (1995) The enhancement of plant growth by free-living bacteria. Can. J. Microbiol. 41:109-117.

Glick B R, C L Patten, G Holguin, D M Penrose (1999) Biochemical and Genetic Mechanisms Used by Plant Growth Promoting Bacteria. Imperial College Press, London, UK. 267 p.

Greenshields L D, L Guosheng, J Feng, G Selvaraj, Y Wei (2007) The siderophore biosynthetic gene SID1, but not the ferroxidase gene FET3, is required for full Fusarium graminearum virulence. Mol. Plant Pathol. 8:411-421.

Halliwell B, J M C Gutteridge (1984) Oxygen toxicity, oxygen radicals, transition metals and disease. Biochem. J. 219:1-14.

Harrington J M, A L Crumbliss (2009) The redox hypothesis in siderophore-mediated iron uptake. Biometals 22:679-689.

Hass D, C Keel, C Reimmann (2002) Signal transduction in plant beneficial rhizobacteria with biocontrol properties. A. Leeuwenhoek 81:385395.

Hassan D G, M Zargar, G M Beigh (1997) Biocontrol of Fusarium root rot in the common bean (Phaseolous vulgaris L.) using symbiotic Glomus mosseae and Rhizobium leguminosarum. Mol. Ecol. 34:7480.

Hissen A H T, A N C Wan, M L Warwas, L J Pinto, M M Moore (2005) The Aspergillus fumigatus siderophore biosynthetic gene sidA, encoding L-ornithine N5-oxygenase, is required for virulence. Infect. Immun. 73:5493-5503.

Hördt W, V Römheld, G Winkelmann (2000) Fusarinines and dimerum acid, mono- and dihydroxamate siderophores from Penicillium chrysogenum, improve iron utilization by strategy I and strategy II plants. Biometals 13:37-46.

Holleman A F, E Wiberg (2001) Inorganic Chemistry. Academic Press. San Diego, CA. 368p.

Inoue K, S Hiradate, S Takagi (1993) Interaction of mugineic acid with synthetically produced iron oxides. Soil Sci. Soc. Amer. J. 57:12541260.

Ishimaru Y, M Suzuki, T Tsukamoto, K Suzuki, M Nakazono, T Kobayashi, Y Wada, S Watanabe, S Matsuhashi, M Takahashi, H Nakanishi, S Mori, N K Nishizawa (2006) Rice plants take up iron as an $\mathrm{Fe}^{3+}$-phytosiderophore and as $\mathrm{Fe}^{2+}$. The Plant J. 45:335346.

Jin C W, G X Li, X H Yu, S J Zheng (2010) Plant Fe status affects the composition of siderophore-secreting microbes in the rhizosphere.
Ann. Bot. 105: 835-841.

Jurkevitch E, Y Hadar, Y Chen (1988) Involvement of bacterial siderophores in the remedy of lime- induced chlorosis in peanut. Soil Sci. Soc. Amer. J. 52:1032-1037.

Jurkevitch E, Y Hadar, Y Chen, M Chinot, S Mori (1993) Indirect utilization of the phytosiderophore mugineic acid as an iron source to rhizosphere fluorescent Pseudomonas. Biometals 6:119-123.

Kawai S, S Tagaki, Y Sato (1988) Mugineic acid-family phytosiderophores in root secretions of barley, corn and sorghum varieties. J. Plant Nutr. 11:633-642.

Kingsley R, W Rabsch, P Stephens, M Roberts, R Reissbrodt, P H Williams (1995) Iron supplying systems of Salmonella in diagnostics, epidemiology and infection. FEMS Immunol. Med. Microbiol. 11:257-264.

Kloepper J W, M N Schroth (1978) Plant growth promoting rhizobacteria on radish. In: Station de Pathologie Vegetale et Phytobacteriologie. Angers (ed). Proc. 4th Int. Conf. Plant Pathogenic Bacteria. INRA, France. pp:879-882.

Kobayashi T, M Suzuki, H Inoue, R Itai, M Takahashi, H Nakanishi, S Mori, N Nishizawa (2005) Expression of iron-acquisition-related genes in iron-deficient rice is co-ordinately induced by partially conserved iron-deficiency-responsive elements. J. Exp. Bot. 56:1305-1316.

Köster W (2001) ABC transporter-mediated uptake of iron siderophores, heme and vitamin B12. Res. Microbiol. 152:291-301.

Krewulak K D, H J Vogel (2008) Structural biology of bacterial iron uptake. Bioch. Biophys. Acta 1778:1781-1804.

Lemanceau P, P Bauer, S Kraemer, J F Briat (2009) Iron dynamics in the rhizosphere as a case study for analyzing interactions between soils, plants and microbes. Plant and Soil 321:513-535.

Lindsay W L (1991) Iron-oxide solubilization by organic-matter and its effect on iron availability. Plant and Soil 130:27-34

Ma J F (2005) Plant root responses to three abundant soil minerals: silicon, aluminum and iron. Crit. Rev. Plant Sci. 24:267-281.

Ma J F, K Nomoto (1996) Effective regulation of iron acquisition in graminaceous plants. The role of mugineic acids as phytosiderophores. Physiol. Plant. 97:609-617.

Ma J F, S Taketa, Y C Chang, K Takeda, H Matsumoto (1999) Biosynthesis of phytosiderophores in several Triticeae species with different genomes. J. Exp. Bot. 334:723-726.

Ma J F, T Shinada, C Matsuda, K Nomoto (1995) Biosynthesis of phytosiderophores, mugineic acids, associated with methionine cycling. J. Biol. Chem. 270:16549-16554.

Madigan M, J Martinko (2005) Brock Biology of Microorganisms. 11th ed. Prentice Hall, New Jersey, USA. $1152 \mathrm{p}$

Marahiel M A (1997) Protein templates for the biosynthesis of peptide antibiotics. Chem. Biol. 4:561-567.

Marschner H, V Römheld, M Kissel (1986) Different strategies in higher plants in mobilization and uptake of iron. J. Plant Nutr. 9:695-713.

Marschner P, D E Crowley (1998) Phytosiderophores decrease iron stress and pyoverdine production of Pseudomonas fluorescens Pf-5 (pvdinaZ). Soil Biol. Biochem. 30:1275-1280.

Meyer I N, D Hohnadel, F Hallé (1989) Cepabactin from Pseudomona cepacia, a new type of siderophore. J. Gen. Microbiol. 135:4791487.

Meyer J M, V Tran, A Stinzi, O Berge, G Winkelman (1995) Ornibactin production and transport properties in strains of Burkholderia vietnamiensis and Burkholderia cepacia (formely Pseudomonas cepacia). Biometals 8:309-307.

Meziane H, I Van der Sluis, L C Van Loon, M Höfte, P A H M Bakker (2005) Determinants of Pseudomonas putida WCS358 involved in inducing systemic resistance in plants. Mol. Plant Pathol. 6:177185.

Miethke M, M Marahiel (2007) Siderophore-based iron acquistion and pathogen control. Microbiol. Molec. Biol. Rev. 71:413-451.

Moeck G, J W Coulton (1998) TonB-dependent iron acquisition: mechanisms of siderophore-mediated active transport. Mol. Microbiol. 28:675-681.

Mori S (1999) Iron acquisition by plants. Curr. Op. Plant Biol. 2:250-253.

Morrissey J A, A Cockayne, P J Hill, P Williams (2000) Molecular cloning and analysis of a putative siderophore $\mathrm{ABC}$ transporter from Staphylococcus aureus. Infec. Immun. 68:6281-6288.

Neilands J B (1995) Siderophores: structure and function of microbial iron transport compounds. J. Biol. Chem. 270:26723-26726. 
Nelson V (2011) Nutrients in compost. Agtech Centre. Alberta Canada. Disponible en http://wwwl.agric.gov.ab.ca/\$department/ deptdocs.nsf/all/eng4466. (Septiembre 2011).

Nomoto K, H Yoshioka, M Arima, S Fushiya, S Takagi, T Takemoto (1981) Structure of 2-deoxymugineic acid, a novel amino acid possessing an iron-chelating activity. Chimia 7:249-250.

Nomoto K, H Yoshioka, T Takemoto, S Fushiya, S Nozoe, S Takagi (1979) Studies on new amino acid possessing an iron-chelating activity from root-washings of some species of Gramineae watercultured. In: 22nd Symp. Chemistry of Natural Products. Fukuoka, Japan. pp:619-626.

O'Sullivan D J, F O'Gara (1992) Traits of fluorescent Pseudomonas spp. involved in suppression of plant root pathogens. Microbiol. Rev. 56:662-676.

Pandey A, F Bringel, J M Meyer (1994) Iron requirement and search for siderophores in lactic acid bacteria. Appl. Microbiol. Biotechnol. 40:735-739.

Perrine F, B G Rolfe, M Hynes, C H Hocart (2004) Gas chromatography mass spectrometry analysis of indolacetic acid and tryptophan following aqueous chloroformate derivatization of Rhizobium exudates. Plant Physiol. Biochem. 42:723-729.

Powell A K (1998) Ferritin: Its mineralization. In: Metal Ions in Biological Systems: Iron Transport and Storage in Microorganisms, Plants and Animals. A Sigel, H Sigel (eds). Dekker, New York. pp:515561

Ran L X, Z N Li, G J Wu, L C Van Loon, P A H M Bakker (2005) Induction of systemic resistance against bacterial wilt in Eucalyptus urophylla by fluorescent Pseudomonas spp. Europ. J. Plant Pathol. 113:59-70.

Ratledge C, L G Dover (2000) Iron metabolism in pathogenic bacteria. Annu. Rev. Microbiol. 54:881-941.

Reichard P U, S M Kraemer, S W Frazier, R Kretzschmar (2005) Goethite dissolution in the presence of phytosiderophores: rates, mechanisms, and the synergistic effect of oxalate. Plant and Soil 276:115-132.

Rodriguez H, R Fraga (1999) Phosphate solubilizing bacteria and their role in plant growth promotion. Biotechnol. Adv. 17:319-339.

Roosenberg J M, L Yun-Ming, L Yong, J M Marvin (2000) Studies and syntheses of siderophores, microbial iron chelators, and analogs as potential drug delivery agents. Curr. Med. Chem. 7:159-197.

Sakaguchi T, N K Nishizawa, H Nakanishi, E Yoshimura, S Mori (1999) The role of potassium in the secretion of mugineic acids family phytosiderophores from iron-deficient barley roots. Plant and Soil 215:221-227.

Saleem M, M Arshad, H Sarfraz, S B Ahmad (2007) Perspective of plant growth promoting rhizobacteria (PGPR) containing ACC deaminase in stress agriculture. J. Ind. Microbiol. Biotechnol. 34:635-648.

Salibury F B, Ross CW (1992) Plant Physiology. Wadsworth, Publishing Co. Belmont, California, USA. 682 p.

Schroth M N, J G Hancock (1982) Disease-suppressive soil and root colonizing bacteria. Science 216:1376-1381

Sessitsch J, X Howieson, H Perret, H Antoun, E Martínez-Romero (2002) Advances in Rhizobium research. Crit. Rev. Plant Sci. 21:323-378

Sharma A, B N Johri, A K Sharma, B R Glick (2003) Plant growthpromoting bacterium Pseudomonas sp strain GPR(3) influences iron acquisition in mungbean (Vigna radiata L. Wilzeck). Soil Biol. Biochem. 35:887-894.

Shojima S, N K Nishizawa, S Fushiya, S Nozoe, T Irifune, S Mori (1990) Biosynthesis of phytosiderophores: in vitro biosynthesis of 2'-deoxymugineic acid from L-methionine and nicotianamine. Plant Physiol. 93:1497-1503.

Sokol P A (1986) Production and utilization of pyochelin by clinical isolates of Pseudomonas cepacia. J. Clin. Microbiol. 23:560-562.

Sugiura Y, H Tanaka, Y Mino, T Ishida, N Ota, M Inoue, H Nomoto, H Yoshioka, T Takemoto (1981) Structure, properties and transport mechanism of iron(III) complex of mugineic acid, a possible phytosiderophore. J. Amer. Chem. Soc. 103:6979-6892.

Sugiura Y, K Nomoto (1984) Phytosiderophores structures and properties of mugineic acids and their metal complexes. In: Siderophores from Microorganisms and Plants. A Chimiak, R C Hider, A Liu, J B Neilands, K Nomoto, Y Sugiura (eds). Springer, Berlin Heidelberg, New York, USA. pp:109-122.

Suzuki M, M Takahashi, T Tsukamoto, S Watanabe, S Matsuhashi, J Yazaki, N Kishimoto, S Kikuchi, H Nakanishi, S Mori, N K Nishizawa (2006) Biosynthesis and secretion of mugineic acid family phytosiderophores in zinc-deficient barley. The Plant J. 48:85-97.

Suzuki M, T Tsukamoto, $H$ Inoue, $S$ Watanabe, $S$ Matsuhashi, $M$ Takahashi (2008) Deoxymugineic acid increases $\mathrm{Zn}$ translocation in Zn-deficient rice plants. Plant Mol. Biol. 66:609-617.

Takagi S (1976) Naturally occurring iron-chelating compounds in oat and rice root washings. Soil Sci Plant Nutrit. 22:423-433.

Takemoto T, K Nomoto, S Fushiya, R Ouchi, G Kusano, H Hikino, S Takagi, Y Matsuura, M Kakudo (1978) Structure of mugineic acid, a new amino acid possessing an iron-chelating activity from roots washings of water-culture Hordeum vulgare L. Proc. Japan. Acad. 54:469-473.

Tortora M L, J C Díaz-Ricci, R O Pedraza (2011) Azospirillum brasilense siderophores with antifungal activity against Colletotrichum acutatum. Arch. Microbiol. 193:275-286.

Ueno D, N Yamaji, J F Ma (2009) Further characterization of ferricphytosiderophore transporters ZmYS1 and HvYS1 in maize and barley. J. Exp. Bot. 60:3513-3520.

Von Wirén N, H Khodr, R C Hider (2000) Hydroxylated phytosiderophore species possess an enhanced chelate stability and affinity for iron(III). Plant Physiol. 124:1149-1157.

Von Wirén N, S Mori, H Marschner, V Romheld (1994) Iron inefficiency in maize mutant ys1 (Zea mays L. cv Yellow-Stripe) is caused by a defect in uptake of iron phytosiderophores. Plant Physiol. 106:7177.

Von Wirén N, V Römheld, T Shioiri, H Marschner (1995) Competition between microorganisms and roots of barley and sorghum for iron accumulated in the root apoplasm. New Phytol. 130:511-521.

Walter A, V Roemheld, H Marschner, D E Crowley (1994) Iron nutrition of cucumber and maize: effect of Pseudomonas putida YC3 and its siderophore. Soil Biol. Biochem. 26:1023-1031.

Wandersman C, P Delepelaire (2004) Bacterial iron sources: from siderophores to hemophores. Annu. Rev. Microbiol. 58:611-647.

Wang Y, H N Brown, D E Crowley, P J Szaniszlo (1993) Evidence for direct utilization of ferrioxamine B in axenically-grown cucumber. Plant Cell Environ. 16:579-585.

Weinberg E D (1997) The Lactobacillus anomaly: total iron abstinence. Persp. Biol. Medic. 40:578-583.

Welbaum G, A V Sturz, Z Dong, J Nowak (2004) Fertilizing soil microorganisms to improve productivity of agroecosystems. Crit. Rev. Plant Sci. 23:175-193.

Winkelmann G (1991) Specificity of iron transport in bacteria and fungi. In: Handbook of Microbial Iron Chelates. G Winkelmann (ed) CRC Press Boca Raton, Florida USA. pp:14-60.

Yehuda Z, M Shenker, V Römheld, H Marschner, Y Hadar, Y Chen (1996) The role of ligand exchange in the uptake of iron from microbial siderophores by gramineous plants. Plant Physiol. 112:1273-1280

Yehuda Z, M Shenker, Y Hadar, Y Chen (2000) Remedy of chlorosis induced by iron deficiency in plants with the fungal siderophore rhizoferrin. J. Plant Nutr. 23:1991-2006.

Yehuda Z, Y Hadar, Y Chen (2012) FeDFOB and FeEDDHA immobilized on sepharose gels as an Fe sources to plants. Plant Soil 350:379391.

Zhang H, Y Sun, X Xie, M S Kim, S E Dowd, P W. Pare (2009) A soil bacterium regulates plant acquisition of iron via deficiency inducible mechanisms. The Plant J. 58:568-577. 